\title{
JEDDAH CITY: A VISUAL IMPRESSION OF NON-FIGURATIVE PUBLIC ART
}

\author{
LINA M. KATTAN \\ College of Art and Design, King Abdulaziz University, Saudi Arabia
}

\begin{abstract}
Contrary to many misconceptions, Islamic ideologies do not contradict modernism or contemporaneity in art; Islam is not absolute conservatism. However, the advent of radical thinking in Islam and the spread of false-hearted interpretations of religious scriptures have indirectly affected visual aesthetics of three-dimensional public art in Jeddah city. Consequently, the aesthetic experience has been disrupted, and the beauty standards by which the city was constructed have been completely marginalized. In the seventies, the selection process of displayed public art reflected Islamic sensibilities and Saudi culture at the time; however, such selection is being disapproved today. In this paper, I argue that abrupt change in Islamic conceptions developed a deviation in its practice; thus, a change has arisen in the definition and identity of non-figurative art in the city of Jeddah. This research focuses on three public monuments that were accused of conflicting with the new waves of radical Islam that have shaped Saudi culture since the late eighties, all of which can be traced to the so-called Islamic Revolution in 1979. This paper briefly discusses the Islamic perception of three-dimensional art (both classic and revised conceptions and attitudes), and how that understanding has affected the public art of Jeddah. Furthermore, this change in Saudi mind-set towards figurative art has affected visual aesthetics and experiences of local inhabitants and has led to increased visual pollution in Jeddah, The Bride of the Red Sea.

Keywords: non-figurative art, representational art, visual aesthetics, visual pollution, threedimensional art, beauty standards, Islamic Revolution, public monuments, statues, Saudi identity.
\end{abstract}

\section{INTRODUCTION}

One significant factor that lead me to a career as an artist was my experience living in a city constructed on the idea of stimulating visual aesthetics. I remember passing by many public sculptures on my way to school every day, such as The Rocket, al-Baslamah, The Sword, The Structure of the Atom, al-Mafrouka, al-Qibla, Tarik Bin Ziayd, The Orange Airplane, and during the weekends we would visit The Corniche and enjoy the numerous public masterpieces outlining the coastline of the Red Sea. In a way, combining natural and artistic beauty has always been a key component of Jeddah's artistic beauty. In this way, it is no surprise Jeddah has been called The Bride of the Red Sea. To many locals, Jeddah city is a woman. She is not only a Bride, but also a grandmother, or jaddah (the Arabic origin of the word). This name was derived from it being the burial place of Eve, the mother of all humans [1].

What gave Jeddah city its renowned character is its outdoor public art. The construction and the urban planning of the city of Jeddah can be summed up in the famous quote: "[t]he happier people of the rising City Beautiful will grow in love for it, in pride in it. They will be better citizens, because better instructed, more artistic, and filled with civic pride" [2]. The Beautification Project of the city stemmed from the notion of associating women with beauty. The thought was to beautify the face of the city by accentuating it with three-dimensional works of art. Such works followed recurrent themes: Islam, calligraphy, geometry, transportation, and stylized figuration. 


\section{URBAN DESIGN OF JEDDAH}

In 646, Caliph Uthman declared Jeddah to be the main passage to Makkah and Medina's pilgrims, thus he surrounded it by a massive wall for protection [3]. Over the years, its small population grew; al-Makdisi described it as "fortified and populated. The people are traders and wealthy [4]. The town is Makkah's treasury and Yemen's and Egypt's emporium" [3]. In the eleventh century, T.E. Lawrence visited the city, and described it in his journals as "a remarkable town" [3]. In 1525, Ottoman sultans rebuilt the walls to defend it from the Portuguese [5]. Later, the opening of the Suez Canal in 1869 brought a great change in Jeddah's commerce, which increased wealth among merchants [1], [6]. Currently, Jeddah has become one of the wealthiest and most multicultural cities in the kingdom. This dramatic change occurred after the oil boom in 1938-which thereby increased its population from 25,000 to about half of a million by the late eighties - and the walls were completely demolished in 1947 [3]. This new and unexpected change paved the way for reconstruction and redesign to fulfill the new needs of that prosperous city.

Mohammed Said Farsi was the aesthetic creator of The Bride of the Red Sea. He was born in Makkah, and he first visited Jeddah when he was five-years old [3]. At the time, he was fascinated by the merging lines of the sea horizon with the limitless blue sky. After studying architecture and town planning in Alexandria (another coastal city), he was appointed by the government to be the Planning Officer for the Western region in 1965, and then became the Mayor of Jeddah in 1972 [3], [6]. Indeed, it is easy to find a correlation between the Ancient Egyptian legend of The Bride of The Nile and Jeddah's nickname chosen by the Mayor. The process of the Master Urban Plan of the Western region started under his supervision and responsibility in 1970 [3].

In the late sixties, Saudi government appointed a committee of British consultants to develop the urban planning of the city [3]. Planning was completed through five phases, which began in 1966 and ended in 1974 [3]. The project started with the development and expansion of the seaport, the airport, the seashore (The Corniche), pipelines and infrastructure. The final phase was the beautification mission to combine function with aesthetic beauty through roads, bridges, and roundabouts. What distinguished Jeddah from other cities was the artistic visions of its planners. "Woven into the fabric of the city was the fulfilment of the requirements for the new Jeddah to provide something fresh and relevant to the modern Islamic world" [3]. Because "[a]rchitects are expressions of the desires of their designers and builders; these forms intend to shape people and thus shape the world" [2]. Distributing public works of art throughout the city, alongside the seafront, and in major roundabouts gave Jeddah its international fame and beauty.

In essence, the urban planning of Jeddah was merely influenced by the Baroque architectural style, in which the layout is designed to display the city's power and wealth through focus on monuments [7]-[9]. Basically, this "axial design emphasizes long formal vistas with strongly defined edges; the vista is frequently terminated by a prominent building or monument. The axis itself is invisible, but the perception it creates" [10]. A good example could be seen in the planning of Washington DC (Figs 1 and 2). Stemming from this concept, the planning of Jeddah was based on placing large sculptures in major intersections to create a continuous visual axis throughout the city. The view of this visual axis should not be blocked, "[a]n axis like this can be reinforced if something is placed at the end of the visual field, such as an obelisk, so that the gaze is drawn to central point in the composition" [11]. Placing colossal three-dimensional works of art in the middle of roundabouts and at the end of the visual axis created a continuous visual experience [12].

The selection process for the three-dimensional public art was not an easy task due to the constraints of Islamic traditions and Saudi cultural sensibilities. To abide by the common 


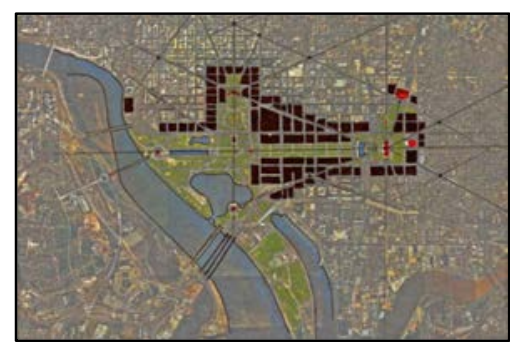

Figure 1: The urban city planning of Washington DC.

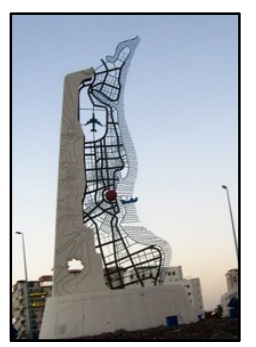

Figure 2: A sculpture conveying the urban planning of Jeddah city.

conventions towards three-dimensional art, Mayor Farsi and his team had to "satisfy the requirements of Saudi culture and environment while at the same time reflecting the situation of the city in the context of world art, both contemporary and ancient" [3]. Mayor Farsi undertook a daunting task, which would inevitably cause distress and tension among city locals. However, the Mayor managed to ensure the provision laid down for the future look of the city, and he succeeded in achieving all the basic requirements and objectives for that project.

As a result, the city of Jeddah became the first city in the world to disregard the common notion that art should only be contained within the museum walls. Mayor Farsi and his team committed "themselves to taking art out into the streets where it was accessible to everybody, whether at leisure or going about his or her business... Jeddah's sculptures and monuments serve as recognisable landmarks and focal points as well as giving delight to those from all directions" [3]. The beautification project of the city focused on creating gardens and open spaces interplayed with many sculptures and monuments to fulfil the needs of its public and to please its inhabitants. Therefore, "Jeddah stands out as an example of how an ancient Arab city can grow and adapt as it enters the twenty-first century" [3]. The plan was to utilize large roundabouts as the construction for major street intersections in Jeddah, and then to simultaneously house huge sculptures for the public to appreciate and enjoy. By the end of the urban planning project, Jeddah, with its numerous modern public art, was awarded the Aga Khan Award for architecture in 1983 [3].

\section{ISLAMIC PERCEPTION OF THREE-DIMENSIONAL FIGURATION}

Perhaps the most long-held controversial Islamic issue is the rulings on creating art. Because art is more emotional than rational, Muslim scholars' attitudes are always divided. While science feeds the brain, art feeds the soul; therefore, art in Islam is meant to elevate not demoralize the human being. For these reasons, a balanced opinion should be advocated, while at the same time, does not contradict the Quranic teachings. It can be summed up in the following quote:

In general, Muslims scholars always divide into two groups: one maintaining that religion should be sacrificed for the sake of modernization, and the other that modernization should be sacrificed for the sake of religion. Between these two groups there is now a third, whose number is increasing, which sees a possibility for reconciliation between modern life and the old religion. The modern Muslim 
thinkers find in the principles of Islam a flexibility which allows them to explain and interpret with the greatest freedom while still keeping the faith intact [12].

This study supports the third balanced conception of contemporary Muslim scholars, which advocates Islamic flexibility to adapt changes of the modern world while at the same time maintaining Islamic faith.

The word statue for instance, was mentioned in the Quran in two different ways: 1) condemned, i.e. worshiped idols: it is stated in the Quran 22:30, "So avoid the uncleanliness of idols and avoid false statement"; and 2) indorsed, i.e. for beautification reasons: As stated in the Quran 34:13, "They made for him [Prophet Solomon] what he willed of elevated chambers, statues, bowls like reservoirs, and stationary kettles. [We said], 'Work, O family of David, in gratitude.' And few of My servants are grateful." Such examples from Quranic scriptures can be challenging, especially for those interpreters who do not have a solid comprehension of the Arabic language.

Because creating three-dimensional figures was always associated with paganism in ancient history, many Muslim scholars forbade the act of creating such works. Moreover, part of the confusion was that many classic scholars relied on hadiths (Prophet Mohammed's sayings), which confused creating art with emulating Allah's act of creation from nonentity. As an example (al-Bukhari \& Muslim, Book 18, Hadith 170), Ibn Abbas said: "I would not tell you except what I heard the Prophet saying, he said: 'Whoever makes any figure, Allah will keep on punishing him until, he insufflates soul in it [that figure] and he will never be able to insufflate it." In this context, the expression 'making figures' correlates with the intention of rivalling Allah in the act of creation. Even though many Muslim scholars might consider two-dimensional figures as permissible, most still ban creating likeness of threedimensional living-beings. In short, traditional readings of Islamic scriptures support aniconism, which is the proscription against creating images of living-beings, namely humans and animals. The traditional Islamic conception of making three-dimensional statues can be summed up into three rulings: 1) strictly prohibited: when artists intentionally create statues of living-being to rival Allah's act of creating from nonentity; 2) permissible but not recommended: making partial-figures (fragmented or incomplete) of living-beings; and 3) permissible: three-dimensional figures created for non-sacred reasons such as children's toys or food.

Contemporary readings of religious scriptures are far more practical/logical than the classic ones. In addition to focusing more on Quranic scriptures than hadiths, Contemporary scholars also extended the reinterpretation. Moreover, contemporary scholars extended the reinterpretation of Quranic verses according to the historical context. The idea of making figurative sculptures is not completely rejected in Islam, but only when it is associated with idolatry. Prophet Abraham in the Quran for example, was not opposed to creating statues of themselves, but he was against the idea of worshiping them instead of Allah. For instance, in the Quran 22:31, "That [has been commanded], and whoever honors the sacred ordinances of Allah - it is best for him in the sight of his Lord. And permitted to you are the grazing livestock, except what is recited to you. So avoid the uncleanliness of idols and avoid false statement." In short, it seems that the focus of prohibition in religious scriptures specifically targets idolatry, not the entire concept of creating statues. While classic and contemporary Muslim scholars have different views on three-dimensional figuration, they share common ground in what is forbidden. For instance, "idolizing and sanctioning images that reach the level of sacredness; overly resembling luxury and sumptuousness; interrupting Muslim prayers; containing nude and sexual content; and of course, when the artist 'intentionally' 
aims to rival Allah in His act of creation from nonentity" [13]. Briefly, they both agree on the ban of idolatry and twisted/distorted intentionality.

In the past, Muslim artists always tried acclimating to the different cultures they encountered. For instance, when the Umayyads settled in Spain, which had a long history of figuration, they did not dismiss such tradition. Instead, they tried to adapt to the local culture; hence, the artists included sculptural tradition in non-religious milieus. In order to avoid creating three-dimensional full-figures living-beings, Muslim artists found a way to produce figurative art by making partial or fragmented figures to escape the prohibition.

Today, adjusting to contemporary art has become easier due to its abstracted forms; therefore, Muslim artists can stay on par with the global art world without contradicting the teachings of Islam. Indeed, abstract, geometric, or non-figurative forms can be Islamic and contemporary at the same time. Moreover, with the spread of balanced interpretations of Islamic scriptures concerning figuration, many Muslim artists now find representational three-dimensional art more acceptable than it was before. As the renowned Egyptian art critic Ashraf Ibrahim declared, "[n]o one for sure is going to worship a statue now. The reason to forbid statues is finished" [14]. In short, a different vision/interpretation is required for a different context. As for the modern Saudi culture, not all Saudi artists approve the rereadings of the Quran; many of whom are still against the idea of creating three-dimensional figures just to be 'on the safe side.'

\section{CONTROVERSIAL PUBLIC ART IN JEDDAH}

During the selection process of three-dimensional public art in the seventies, Mayor Farsi made sure to abide by both religious and cultural traditions. However, such selection is being disapproved today. With the shift toward radicalism in Islamic ideologies that have shaped Saudi culture since the late eighties, some of the public monuments were accused of conflicting with the new waves of Islam, all of which can be traced to the so-called Islamic Revolution in 1979. Due to limited space in the paper and to the difficulty of obtaining information (for corruption and negligence reasons), this paper is only focusing on three public sculptures in Jeddah: The Thumb, The White Steed, and Jeddah, The Bride of The Red Sea.

Firstly, one of the most notorious sculptures of Jeddah was The Thumb (Fig. 3). This work of art was created by the renowned French sculptor Baldaccini César (1921-1998). In the early sixties, he joined the art movement called Nouveau Réalisme (Neo-Realism), which focused on depicting reality through the use of daily materials instead of traditional ones [15]. In 1966, he started experimenting with new materials - such as resin and fiberglass - and created a solo exhibition on the theme of the hand [15]. The Thumb still remains one of his iconic works. This thumb was originally based on a life-size cast (forty-centimeters) of the artist's own thumb (Fig. 4), and then was "scaled up using the machines traditionally employed by sculptors to enlarge their works. César made several, increasingly higher versions of this work" [15]. For instance, a large-scale model (twelve-meters) was on the esplanade de La Défense in Paris titled Le Pouce (The Thumb), and the smaller-scale version was located in Jeddah [16].

Jeddah's thumb sculpture used to stand in the intersection of Prince Majid Street and Granada Road. A six-meter high artwork was created by using everyday found objects, compressed, and then enlarged. When asked about César, Mayor Farsi stated, "in this harsh environment great artists were driven to create beauty out of ugliness, transforming scrap iron and other waste materials into works of art which stand as prominent landmarks in the history of contemporary art" [3]. César continued to do these synthetic sculptures in Jeddah, 


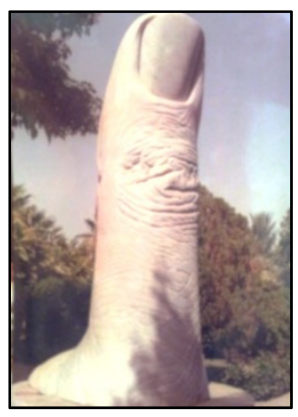

Figure 3: Baldaccini César, The Thumb, unknown date.

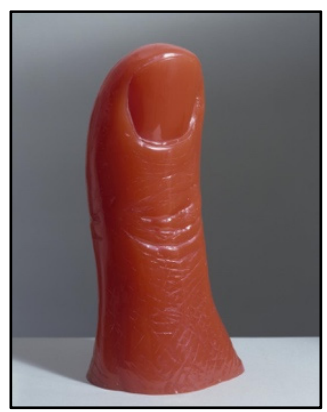

Figure 4: Baldaccini César, Thumb (resin cast), 1966.

which he called amalgams, such as The Fist (at Prince Sultan Road) and The Eye (at alHamrah Corniche).

Unlike the Paris version, Jeddah's Thumb is smaller in scale and stands on a white marble pedestal. Even though it is smaller than its French counterpart, the larger than life aspect gives it a sense of prestige. One can notice the tiny and elaborative details of the skin with all its pores and wrinkles. Unusually, the sculpture was painted with an unnatural all-over white color and was surrounded with greenery. This symbolic color may indicate lifelessness, which is a significant feature of the work (to be discussed later). Even though César was influenced by Neo-Realism, reality only existed in the materials and the details. For some, the way the thumb stands is unsettling. With its closed silhouette, it stands straight like an Egyptian obelisk with its all-around carved details. This way of posture could have been the sole problem of its controversy.

Two years after installation, it was demanded that The Thumb be removed from public view. Controversy started thirty years ago when Jeddah locals started to associate The Thumb with an offensive connotation due to its phallic semblance. It was socially known as Farsi's Finger, which stirred many conservatives to demand its removal. To avoid further disputes, the Mayor finally removed it, and then kept it in his home as one of his private collections. Due to the propaganda surrounding it, many elite members of the Saudi society were eager to own it. It was finally sold in 2004 to the Syrian artist Rabi al-Akhras for about one million Riyals [17]. In this regard, al-Akhars stated, "as a coincidence, I found this [The Thumb] sculpture in one of marble factories while I was looking to buy some marble for one of my future works. However, it was broken in two places. Without hesitation, I bought it. Now, it is in my own home because I know that it is the second most important sculpture that César made. He created a series of twelve thumbs; this version is about six-meters high" [17]. The good news is that the sculpture survived after it had been missing for years without a trace.

Even though Mayor Farsi adhered to Islamic and cultural traditions when selecting The Thumb as public art, new-waves of conservatism did not approve of it. At the time, it seemed that Farsi deliberately selected a fragment of a figure to avoid the pervasive prohibition regarding three-dimensional figuration. Moreover, the all-over white color of the sculpture made it appear lifeless, which is another technique to escape the idea of constructing fullfigure living-beings. All of these measures did not satisfy conservative Saudis to allow that sculpture to be publicly displayed. While there are other partial-figure sculptures in Jeddah done by César such as The Fist and The Eye, the argument only surrounded The Thumb due to its sexual association. 
Secondly, The White Steed is a famous Jeddah sculpture that was created by the artist Rabi al-Akhras (Fig. 5). Legend has it that the inspiration for this artwork came from a desktop ornament [17]. The sculpture was placed in a large roundabout at the intersection of Hera Street and Prince Fahad Road. Similar to The Thumb, this work of art was requested to be removed from public display mainly for religious reasons. The monument was made from a local stone and consisted of abstracted heads of horses of different sizes, besides some stylized swords and spears. Similar to The Thumb, the work was painted with all-over white color, hence the name. Standing on a two-meter grey marble pedestal, The White Steed was about twelve-meters high (according to some locals). The main sword stood high in the middle of the composition crossing the large horse's head, which gave the sculpture its symmetrical appearance. The unpolished surface with its tactile qualities accentuated the harsh environment of the desert as an inconvenient battlefield. The sculpture was meant to be seen from multiple angles that were equally interested to the viewer.

Not long after, The White Steed roundabout no longer contained white horses. Instead, the sculpture was replaced by several steel boats with open sails because many conservative residents still conform to the well-known prohibition of figuration, either in two or threedimensional forms [18]. Mayor Farsi made sure to commission fragmented and abstracted figures to adhere to cultural sensibilities; however, such adherence was not enough years later. To submit to his opponents, the monument was removed and then replaced with three boats with a large open-frame of steel sails. Apparently, the idea of replacing ships instead of horses was associated with the first ship that brought Muslim pilgrims to Jeddah's Islamic harbor. That ship was named The White Steed. Oddly, the Municipality of Jeddah (al-Amana) denies the existence of that sculpture and claims that it was an imaginary tale fabricated by the residents [19]. Moreover, Jeddah Municipality changed the roundabout sign to Ships instead, but the locals still use the former name (Fig. 6). Today, that replaced sculpture with its ships and sails was completely removed to minimize traffic congestion. By the time Hani Farsi documented the accomplishments of his father in 1991, The White Steed roundabout was documented in his book as Sails to erase the previous name from history.

Paradoxically, the same sculptor was later granted permission to create a similar work of art with abstracted and fragmented horses to be placed at King Abdul-Aziz roundabout, which is known to be the largest roundabout worldwide (a diameter of about two-kilometers). Rabi al-Akhras was commissioned to create The Unification Epic, which is a monument dedicated to King Abdul-Aziz's triumph over the Arabian Peninsula. This massive artwork towers twenty-meters into the sky. Even though conservative Saudis are now stricter than they were thirty years ago, there are no complaints from the public. One theory suggests that public constraints on 'freedom of speech' might be a huge factor in this situation. Later, similar sculptures could be publicly displayed, but still as fragmented pieces (not as fullfigures) to avoid the prohibition against figuration. With all its surrounding controversies, there are no documented photographs of The White Steed, except for its resemblance to the later piece called Horses and Spear by the same artist.

Finally, another scandalous three-dimensional public art in Jeddah was called Jeddah, Bride of the Red Sea (Fig. 7). Ironically, this sculpture had publicly survived longer than expected. This sculpture was fashioned by the Egyptian artist Mahmoud Banat. It was carved from white marble and was located on The Corniche area that runs along the shoreline of the Red Sea.

Jeddah, Bride of the Red Sea work of art was influenced by two major elements: the anchor and Arabic calligraphy. The overall composition was a ship anchor sitting vertically on a wavy seabed with a thick rope wrapped around it to harmonize the artwork with the 


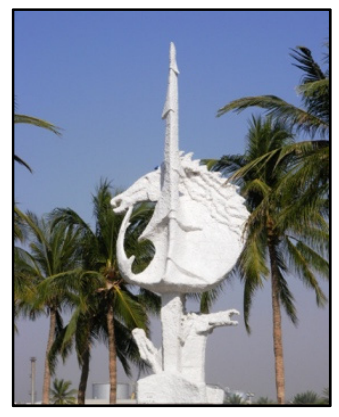

Figure 5: Rabi al-Akhras, assumed replica of The White Steed, unknown date.

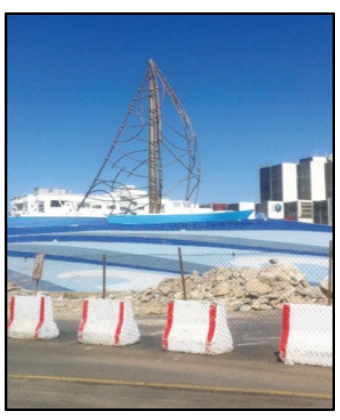

Figure 6: Unknown artist, Ships, unknown date.

surrounding coastal environment. The Arabic words 'Jeddah, the Bride' took the form and space of the horizontal lower part of the anchor. Oddly, it seems that the sculpture was intended to be on a different base because it was slightly larger than the pedestal that was used. The pedestal combined cement and scattered brown pebbles to form a headless pyramid. To avoid blocking the scenic seafront view, it was not meant to be a large sculpture; it stood no more than two-meters high and was set on a pedestal with similar height. The sculpture was mainly meant to be seen from the front so that the corniche visitors could enjoy looking at both the sea and the artwork.

With the unrealistic shift in Islamic ideologies in the early nineties, a rumor was circulated among the locals that ship anchors were another religious symbol of the cross and crucifixion. Due to its right angles and to the different line lengths, the sculpture recalled in people's minds an upside-down cross. Moreover, the two sides of the horizontal lines of the anchor resemble erected male genitalia, especially with the emphasized heads at both ends. These sacrilegious and sexual connotations stirred the public's opinions regarding the artwork. At the beginning, some extremists demanded its removal, but the authorities did not comply to their irrational opposition. In fact, the extremists tried many times to convince the city's personnel to remove it but had no luck. Currently, it has been completely removed; however, no one knows whether it was done officially or by an unsanctioned individual. Indeed, some locals believe that it was illegally removed and others say it was stolen. In either case, the pedestal now stands empty and artless. Unfortunately, what is left is only the steel bar that was holding the sculpture in.

Compared to another statue titled Jeddah, The Red Sea Bride, created by Mohammed Raif and located under The Squared Bridge in Medina Road, one would predict that it would be removed a long time ago (Fig. 8). This artwork is basically a headless body of a sea-mermaid that is holding between her hands a large circular disk high up in the sky and contains the Arabic words 'Jeddah, the Bride of the Sea.' Even though it is a figurative sculpture of an abstracted topless 'female,' it did not cause major controversies like the ship anchor. One rational explanation could be that the high level of abstraction with the discreet location did not trigger any objections. To be sure, many opponents did try to get it removed, but luckily, authorities did not comply with such absurdities.

With the three examples of non-figurative public art discussed previously - The Thumb, The White Steed, and Jeddah, The Bride of the Red Sea - one could really understand the radical change in Islamic and cultural sensibilities since the late eighties in the Kingdom. The 


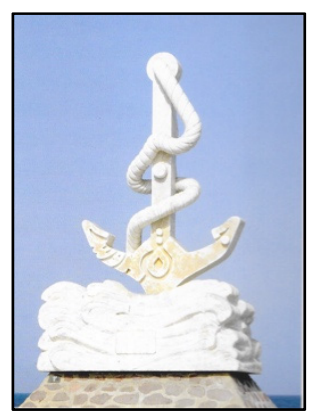

Figure 7: Mahmoud Banat, Jeddah, Bride of the Red Sea, unknown date.

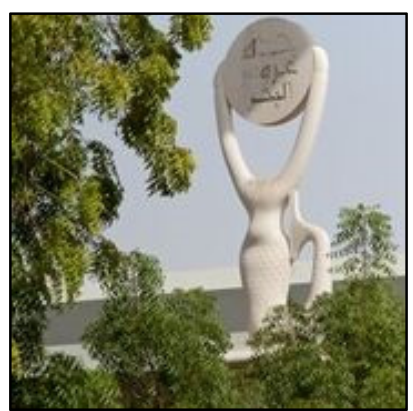

Figure 8: Unknown artist, Jeddah, The Red Sea Bride, unknown date.

spread of misleading interpretations of religious scriptures have indirectly affected visual aesthetics of three-dimensional public art in the city of Jeddah. Consequently, the aesthetic experience has been disrupted, and the beauty standards by which the city was constructed have been completely marginalized. Even though the selection process of displayed public art in the seventies (pioneered by Mayor Farsi and his team) reflected Islamic sensibilities and Saudi cultural traditions at the time, such selection is being disapproved today with the major shift in religious thinking. Mayor Farsi was keen to follow religious and cultural traditions, and it was indeed acceptable by the public at the time. Nevertheless, the sudden change in such traditions affected the art scene in the Kingdom at large. Luckily, and with the re-evaluation of past constraining Islamic interpretations, contemporary Muslim scholars are shedding light on such fallacies.

Contrary to misconceptions, Jeddah city still has many figurative sculptures of full-figure living-beings. For example, there are sculptures that consist of naturalistic flocks of small birds (Migrant Birds by Sylvestre Giovanni) or fish (School of Dolphins by unknown artist). Nonetheless, human figuration continues to be absent from the public scene. Regrettably, even in modern-day Saudi, creating full-figured humans could still be considered religiously and socially unacceptable.

\section{VISUAL POLLUTION IN JEDDAH}

According to Jeddah Municipality, about 620 public artworks have been located, identified, and then documented; however, about 200 of them are still unrecognized [20]. Many of these public works were removed to make more space for traffic and for reconstruction purposes. About 62 works are being relocated, many others are kept in the Municipality's storeroom awaiting decisions, and twelve of the artworks have unspecified locations [5], [20]. It has been documented that these public works of art (including ten murals) scattered around the city worth an estimated three billion Saudi Riyals [21].

Due to inadequate attention and consideration, many of the public sculptures are either missing or stolen. What remains is some pictures or vague memories from locals. For these reasons, in 2011, al-Amana initiated The Beautification Advisory Art Committee (consists of fifteen artists: eleven males and four females) to document what is left and to be responsible for any future decisions concerning the public art [21]. After investigation, the committee divided Jeddah sculptures into three categories: 1) works done by renowned international artists that are valuable and need professional care when handling and restoring; 2) moderate-value works that were mistakenly believed to be the work of famous artists; and 
3) low-quality works that were done poorly and did not survive the severe weather conditions. Despite the sincere investigations, the displacement and removal of Jeddah's monuments remained vague. Besides lack of attention and theft, severe weather conditions and absence of infrastructure accelerated the process of decay, "[f]loods and fires have accomplished what years of neglect and abandonment had not" [1]. Now, many of the public art that was set in the early seventies are in deplorable/terrible condition.

Many of the well-known public monuments and sculptures were displaced to make room for wider roads, but others have gone missing and disappeared without explanation. Some official personnel claim that these works were moved due to the reconstruction projects to expand crowded roads, one such example is The Ratchet Spanner (unknown artist). According to the forthcoming 25 -year Jeddah civil plan, al-Amana is planning to remove all the sculptures placed in the roundabouts and intersections, whether they hinder traffic or not [1]. The project started by removing the smaller art first due to the lower initial cost. Unfortunately, authority personnel minimized restoration and maintenance of Jeddah Corniche and its beautiful sculptures, so it became a habitat of unwanted creatures such as rats and insects.

That beautiful face of modernized Jeddah is fading/decaying due to many reasons such as the population boom, the need for reconstruction, corruption, decision-makers lacking artistic ardor, and vandalism. In other words, Jeddah city has become a Weeping Beauty, which brings to mind Picasso's Girl Before Mirror, 1932. Like Picasso's girl, Jeddah has two realities: past (left image) and present (right image). On the left, the girl seems confident and powerful in which she is adorned and portrayed in daylight, wherein on the right image, she appears masked in darkness, abandoned, and full of flaws. Some binary oppositions can be interpreted from the painting such as young/old, past/present, clear/blurry, confident/ powerless, and beautiful/ugly. Jeddah city has become a decadent face that is lamenting in silence.

\section{RECOMMENDATIONS}

Jeddah municipality should:

- Hire professional staff members to take care of, maintain, and restore its valuable sculptures and monuments.

- Supervise the areas surrounding public sculptures, and monitor all social events initiated nearby.

- Provide information on-site about the works of art such as the artist's name, the work's title and date, and some brief information about the artist's biography and the artistic history behind the work.

- Provide biographical and artistic background information online to make it accessible to all public members.

- Establish an organization or a committee that is responsible for the artworks' theft cases, restoration process, maintenance schedules, and copyright issues.

- Create civil laws concerning the issues related to destruction, vandalism, and robbery.

\section{REFERENCES}

[1] Danforth, L.M., Crossing the Kingdom: Portraits of Saudi Arabia, University of California Press: Oakland, CA, 2016.

[2] Graham, W., Dream Cities: Seven Urban Ideas That Shape the World, Harper Collins: Gloucestershire, 2016.

[3] Farsi, H.M., Jeddah City of Art: The Sculptures \& Monuments, Stacey International: London, 1991. 
[4] Tawal, G., Discover Saudi Arabia (Ektashif al-Saudia), King Fahad National Library: Riyadh, 2009.

[5] Booth-Clibborn Editions, Art Jameel, Sculptures of Jeddah: Twentieth-Century Sculpture in the Arabian Peninsula, Booth-Clibborn Editions: London, 2015.

[6] Khidr, K., Jeddah: Museum Under the Sun, King Fagad National Library: Riyadh, 2007.

[7] Bayyomi, A., Architectural Value \& Fine Art (al-Qima al-Me'amariya wa al-Fan alTashkeeli), Dar al-Ratib al-Jami'eyah: Alexandria, 2002.

[8] Sudjic, D., The Language of Cities, Penguin Random House: London, 2016.

[9] Melvin, J., Isms: Understanding Architectural Styles, Universe Publishing: New York, 2006.

[10] Gaston, G., The Plan of Nashville: Avenues to a Great City, Vanderbilt University Press: Nashville, TN, 2005.

[11] Denslagen, W., Romantic Modernism: Nostalgia in the World of Conservation, Amsterdam University Press: Amsterdam, 2009.

[12] Husseini, I., Islam Past and Present, 1956. www.theatlantic.com/magazine/archive/ 1956/10/islam-past-and-present/376245/. Accessed on: 23 Nov. 2017.

[13] Kattan, L., The Conflicted Living Beings: The Performative Aspect of Female Bodies' Representations in Saudi Painting and Photography, 2015. https://tu-ir.tdl.org/ttu$\mathrm{ir} /$ bitstream/handle/2346/63583/KATTAN-DISSERTATION-2015.pdf?sequence=1. Accessed on: 14 Nov. 2017.

[14] Brandstatter, T., The Issue of Sculptures in Islam. http://classroom.synonym.com/theissue-of-sculptures-in-islam-12086686.html. Accessed on: 23 Nov. 2017.

[15] Tate, César Baldaccini: Thumb 1965, 2017. www.tate.org.uk/art/artworks/cesarthumb-t00819. Accessed on: 21 Nov. 2017.

[16] Paris La Defense Art Collection, César: Le Pouce. http://parisladefenseart collection.com/en/routes/48. Accessed on: 21 Nov. 2017.

[17] Makkah Newspaper, The Bride Gave Up Her Beauty (al-Arous Tatanazal An Jamalaha), 2 Mar. 2014. http://makkahnewspaper.com/article/15464/Makkah. Accessed on: 22 Nov. 2017.

[18] al-Bogami, F., The White Horse Gets Off After Three Decades in Jeddah, 18 Jan. 2013. $\mathrm{http}: / /$ archive. aawsat.com/details.asp? section $=43 \&$ article $=713530 \&$ issueno $=12470 \#$. WhWQ-rSZ3Vo. Accessed on: 22 Nov. 2017.

[19] al-Sabban, D., Looking For 12 Missing Sculptures in Jeddah, 11 April 2008. http://archive.aawsat.com/details.asp?section $=43 \&$ article $=466419 \&$ issueno $=10727 \#$. WhWQRLSZ3Vo. Accessed on: 22 Nov. 2017.

[20] Mohammed, T.B., Jeddah, You Break My Heart, 2011. http://tahanimn.blogspot.com/ 2011/12/blog-post_01.html. Accessed on: 23 Nov. 2017.

[21] Shirayah, A., Initiating Beautification Advisory Art Committee of 15 Male \& Female Artists, 3 April 2011. http://archive.aawsat.com/details.asp?section=43\&article= 615534\&issueno=11814\#.WfYt3BOCzVo. Accessed on: 22 Nov. 2017. 